\title{
Prevalence of Lumbar Disc Herniation in Adolescent Males in Seoul, Korea
}

\author{
- Prevalence of Adolescent LDH in Seoul, Korea-
}

\author{
Do-Keun Kim', Chang Hyun $\mathrm{Oh}^{2}$, Myoung Seok Lee ${ }^{2}$, Seung Hwan Yoon', \\ Hyung-chun Park ${ }^{1}$, Chong Oon Park ${ }^{1}$ \\ ${ }^{1}$ Department of Neurosurgery, College of Medicine, Inha University, Incheon, \\ ${ }^{2}$ Seoul Regional Military Manpower Administration, Seoul, Korea
}

Objective: The authors surveyed the prevalence and the clinical character of lumbar disc herniation (LDH) in Korean male adolescents, and the usefulness of current conscription criteria.

Methods: The data of 39,673 nineteen-year-old males that underwent a conscription examination at the Seoul Regional Korean Military Manpower Administration (MMA) from October 2010 to May 2011 were investigated. For those diagnosed as having lumbar disc herniation, prevalences, subject characteristics, herniation severities, levels of herniation, and modified Korean Oswestry low back pain disability scores by MMA physical grade were evaluated. The analysis was performed using medical certificates, medical records, medical images, and electromyographic and radiologic findings.

Results: The prevalence of adolescent LDH was $0.60 \%$ (237 of the 39,673 study subjects), and the prevalence of serious adolescent LDH with thecal sac compression or significant discogenic spinal stenosis was $0.28 \%$ (110 of the 39,673 study subjects). Of the 237 adolescent LDH cases, $105(44.3 \%)$ were of single level LDH and 132 (55.7\%) were of multiple level LDH, and the L4-5 level was the most severely and frequently affected. Oswestry back pain disability scores increased with herniation severity $(p<0.01)$, and were well correlated with MMA grade.

Conclusions: In this large cohort of 19-year-old Korean males, the prevalence of adolescent LDH was $0.60 \%$ and the prevalence of serious adolescent $\mathrm{LDH}$, which requires management, was relatively high at $0.28 \%$. MMA physical grade was confirmed to be a useful measure of the disability caused by LDH.

Key Words: Lumbar disc herniation $\cdot$ Adolescent $\cdot$ Prevalence $\cdot$ Conscription

\section{INTRODUCTION}

Lumbar disc herniation (LDH) is a common disorder among adults with a degenerative spinal change, and has a reported lifetime occurrence as high as $40 \%{ }^{10)}$. However, the true frequency of this condition in adolescents has not been precisely defined, though it is generally believed to be much lower than in adults, because adolescents tend to have healthier spines and a more robust physiological nature. Studies conducted on $\mathrm{LDH}$ in adolescents during recent years have substantially increased our understanding of this entity, but nevertheless, in-

- Received: June 21, 2011 • Revised: September 25, 2011

- Accepted: October 9, 2011

Corresponding Author: Seung Hwan Yoon, MD, PhD

Department of Neurosurgery, Inha University Hospital, 7-206, 3-Ga,

Shinheung-dong, Jung-gu, Incheon 400-711, Korea

Tel: +82-32-890-2370, Fax: +82-32-890-2374

E-mail: nsyoon@gmail.com formation on adolescent LDH is sparse. Moreover, to ensure a fair means of conducted conscription in Korea, an understanding of the characteristics of $\mathrm{LDH}$ in adolescent males is needed. This study was undertaken to determine the prevalence and the clinical character of lumbar disc herniation in a large cohort of 19-year-old Korean males and to determine the usefulness of current conscription criteria.

\section{MATERIAL AND METHODS}

All Korean men are examined for conscription by the Military Manpower Administration at age of 19. This cross-sectional survey was conducted at the Military Manpower Administration from total of 39,673 males at age of 19 year old in Seoul from October 2010 to May 2011. We retrospectively reviewed all office charts of who submitted medical certificate for adolescent $\mathrm{LDH}$ with medical records and imaging test. When clinical manifestations did not correlate with radiolo- 
gical findings, all medical certificates for adolescent LDH with medical records and imaging test findings (MRI or CT) and electromyographic results were retrospectively reviewed. In addition, the modified Korean Oswestry low back pain disability questionnaire was administered to all study subjects. One radiologist and one neurosurgeon jointly made diagnostic decisions.

We classified adolescent LDH into four groups of herniation severity as is required by the guideline issued by the Korean military directorate, as shown in Fig. 1 and Table 1. According to the guideline, medical conditions are assigned to seven Military Manpower Administration (MMA) physical grades. Normal disc with no signal change in MRI and no disrupted disc material was defined as physical grade 1. Mild disc bulging without compression of thecal sac was considered as grade 2 (Fig. 1A, 1B). Disc protrusion or extrusion without compression of thecal sac was classified to grade 3 (Fig. 1C, 1D). Disc protrusion or extrusion with compression of thecal sac was considered to grade 4 (Fig. 1E, 1F). If thecal sac compression was ambiguous, additional electoromyogram test was applied to examinees. A positive electromyogram test was defined as matched radiculopathy finding in terms of the level suspicious for herniation.; Disc protrusion or extrusion with canal compromise more than $50 \%$ at the mid-sagittal diameter (front to back) in the same plane was defined as grade 5 (Fig. 1G). Disc protrusion or extrusion with positive cut-off sign, the loss of neuromuscular signal at the level of interest identified by imaging, was also classified as grade 5 (Fig. 1H).

For the purposes of the present study, grade 1-2 was considered mild herniation, grade 3 as moderate herniation, grade 4 as severe herniation, grade 5-6 as very severe herniation, and grade 7 as considered as the necessary of recheck about the physical condition. A history of simple discectomy or of a spinal procedure was not considered, and preoperative herniation severities were used to confirm MMA grades. Subjects with other spinal diseases, such as, ankylosing spondylitis, spondylolisthesis, spondylolysis, Shermann's nodules, limbus fractures, lumbarization, and scoliosis, were excluded from the study.

The prevalences of adolescent LDH were analyzed according to the guideline issued by the Korean military directorate herniation severities. Level of herniation distribution was also determined. The relation between Modified Korean Oswestry low back pain scores and MMA grades was analyzed. Statistical significances between herniation severity groups were examined by simple linear regression analysis. Tests were considered significant when $\mathrm{p}$-values were $<0.05$, and the analysis was conducted using SPSS ver. 12.0 (SPSS Inc, Chicago, IL). This study was conducted with the approval of the Military Manpower Administration in Seoul.
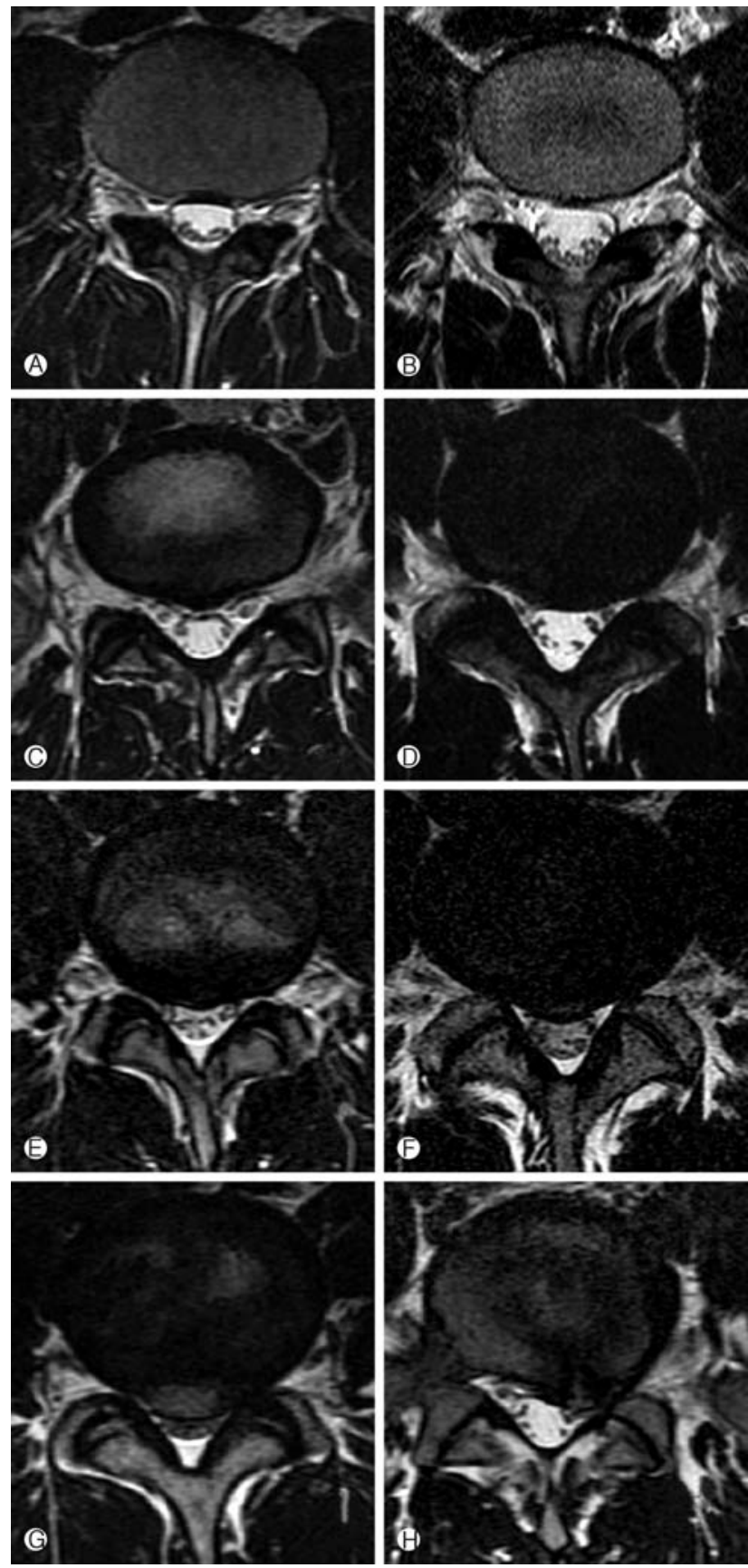

Fig. 1. Images of categories of adolescent herniated lumbar discs in accordance with the guideline issued by the Korean military medical directorate. Mild disc bulging without compression of thecal sac was considered as grade 2 (A, B). Disc protrusion or extrusion without compression of thecal sac was classified to grade 3 (C, D). Disc protrusion or extrusion with compression of thecal sac was considered to grade $4(E, F)$. Disc protrusion or extrusion with canal compromise more than $50 \%$ at the mid-sagittal diameter in the same plane was defined as grade $5(\mathrm{G})$. Disc protrusion or extrusion with positive cut-off sign, the loss of neuromuscular signal at the level of interest identified by imaging, was also classified as grade $5(\mathrm{H})$. 
Table 1. Classification of adolescent herniated lumbar disks as required by guideline issued by the Korean military medical directorate

\begin{tabular}{lcc}
\hline \hline Status of lumbar disc herniation & MMA grade & Physical severity \\
\hline Normal disc & 1 & Mild \\
Mild disc bulging without compression of thecal sac & 2 & Mild \\
Disc protrusion or extrusion without compression of thecal sac & 3 & Moderate \\
Disc protrusion or extrusion with compression of thecal sac ${ }^{*}$ & 4 & Severe \\
Disc protrusion or extrusion with canal compromise more than $50 \%^{+}$ & 5 & Very severe \\
Disc protrusion or extrusion with positive cut-off sign $^{*}$ & 5 & Very severe \\
\hline
\end{tabular}

*A positive electromyogram test was defined as matched radiculopathy finding in terms of the level suspicious for herniation; ${ }^{+}$spinal canal stenosis was defined as the narrowing of the spinal canal by $>50 \%$ of the mid-sagittal diameter (front to back) in the same plane; ${ }^{\ddagger}$ cutoff was defined as the loss of neuromuscular signal at the level of interest identified by imaging.

Table 2. The prevalence of a herniated lumbar disk in 19-year-old males

\begin{tabular}{|c|c|c|c|}
\hline & \multicolumn{3}{|c|}{ "Herniated lumbar disk } \\
\hline & No. of cases & Percent & Accumulate \% \\
\hline Total 19 years old male examinees of conscription & 39,673 & & \\
\hline Total herniated lumbar disk & 237 & $0.60 \%$ & \\
\hline Very severe herniated lumbar disk & 12 & $0.03 \%$ & $0.03 \%$ \\
\hline Severe herniated lumbar disk & 98 & $0.25 \%$ & $0.28 \%$ \\
\hline Moderate herniated lumbar disk & 64 & $0.16 \%$ & $0.44 \%$ \\
\hline Mild herniated lumbar disk & 63 & $0.16 \%$ & $0.60 \%$ \\
\hline
\end{tabular}

\section{RESULTS}

The results of this study are summarized in Table 2. Of the 39,673 study subjects, 237 were diagnosed as having adolescent lumbar disk herniation (LDH), and thus, the estimated prevalence of adolescent $\mathrm{LDH}$ in our population was $0.60 \%$. The prevalence of very severe $\mathrm{LDH}$ was $0.03 \%$, of severe $\mathrm{LDH}$ was $0.25 \%$, and of moderate and mild $\mathrm{LDH}$ was $0.16 \%$. The estimated prevalence of serious adolescent $\mathrm{LDH}$ with thecal sac compression or significant discogenic spinal stenosis was $0.28 \%$. In this study, 9 cases were examined after the surgery; 7 cases underwent on an open discectomy, 1 case underwent on artificial disc insertion, and 1 pedicle screw fixation.

One thousand one hundred eighty-five disc levels were investigated during the study. Out of the 237 adolescent $\mathrm{LDH}$ cases, 105 cases (44.3\%) had single level LDH and 132 cases (55.7\%) had multiple level LDH (Fig. 2). Out of the 1185 disc levels, 500 were checked for disc status for reasons ranging from bulging to severe spinal canal stenosis. The distribution of the 500 disc levels is shown in Table 3. According to the affected disc level, the distribution was shown in L5-S1 as $40.8 \%$, L4-5 as 50.6\%, L3-4 as 6.4\%, L2-3 as 1.8\%, and L1-

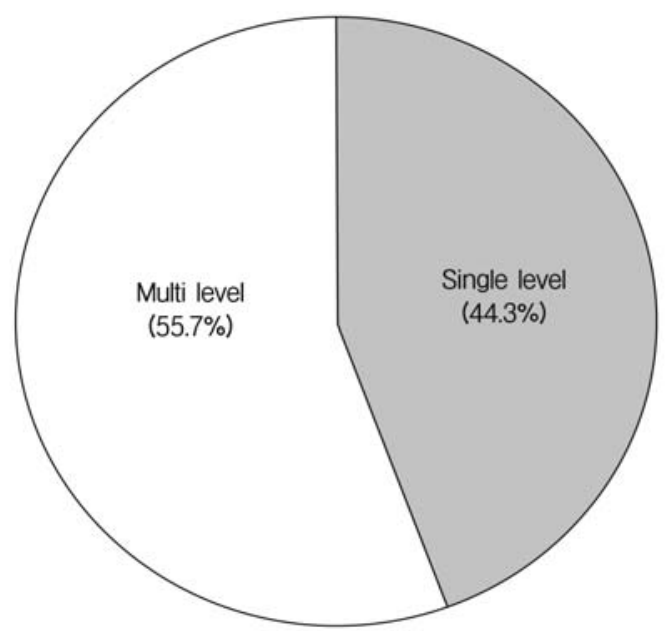

Fig. 2. Single and multilevel percentage of 1185 disc levels among 237 19-year-old male examinees.

2 as $0.4 \%$ (Fig. 3). According to severity of disc, the distribution was checked as $36.8 \%$ in mild herniation, $33.8 \%$ in moderate herniation, $26.8 \%$ in severe herniation, and $2.6 \%$ in very severe herniation (Fig. 4). In terms of herniation severity, severe and very severe herniation were present at 29.4 $\%$ of affected levels; the L4-5 level was the most frequently 
Table 3. Distribution and severity of herniated lumbar disc segments for the 237 herniated lumbar disc cases (1,185 disc segments)

\begin{tabular}{|c|c|c|c|c|c|}
\hline \multirow{2}{*}{ Location } & \multicolumn{4}{|c|}{ Severity according to MMA physical grade } & \multirow{2}{*}{ Total } \\
\hline & Mild & Moderate & Severe & Very severe & \\
\hline $\mathrm{LI} / 2$ & 1 & 1 & - & - & $2(0.4 \%)$ \\
\hline$L 2 / 3$ & 4 & 5 & - & - & $9(1.8 \%)$ \\
\hline$L 3 / 4$ & 17 & 11 & 3 & 1 & $32(6.4 \%)$ \\
\hline$L 4 / 5$ & 86 & 83 & 76 & 8 & $253(50.6 \%)$ \\
\hline L5/S1 & 76 & 69 & 55 & 4 & $204(40.8 \%)$ \\
\hline Total & $184(36.8 \%)$ & 169 (33.8\%) & 134 (26.8\%) & $13(2.6 \%)$ & 500 \\
\hline
\end{tabular}

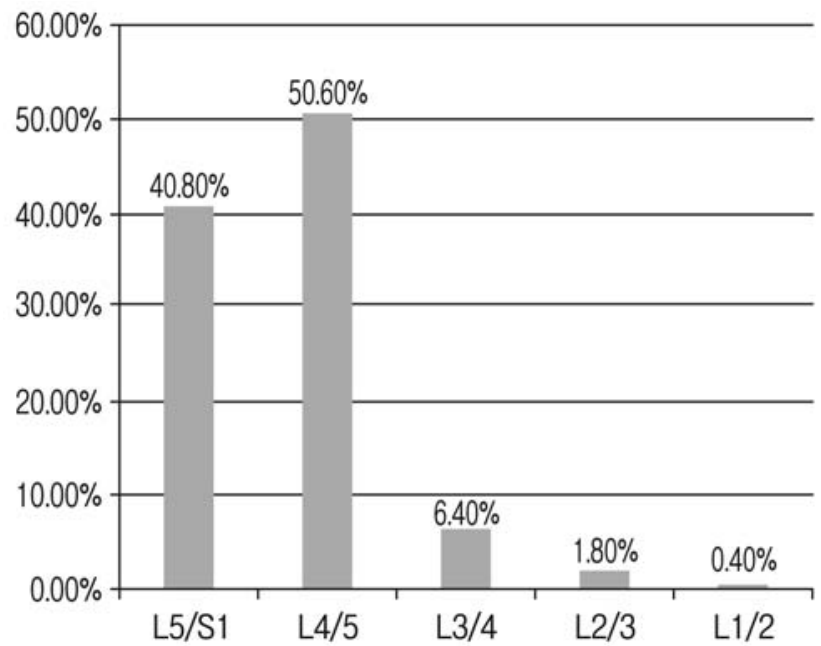

Fig. 3. Disc level distribution of herniated lumbar disc segments for the 237 herniated lumbar disc cases (1185 disc segments).

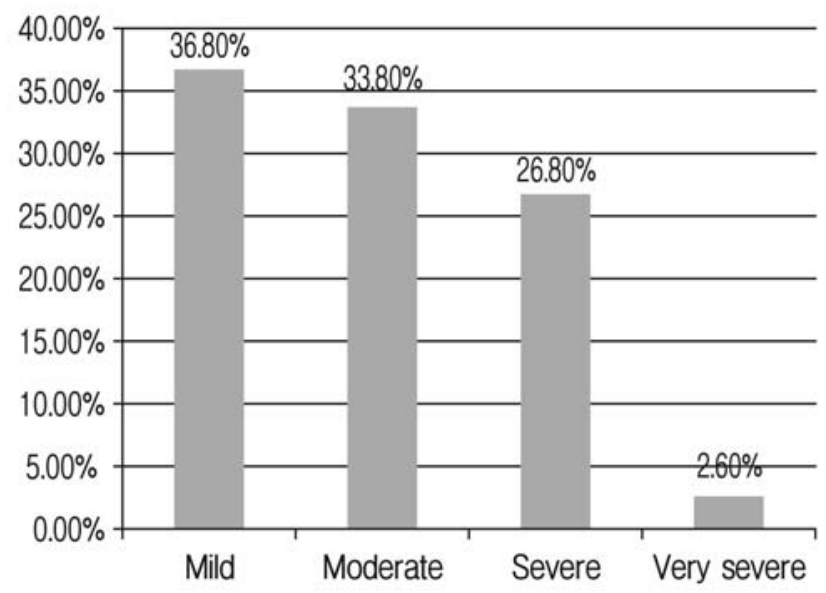

Fig. 4. Distribution of herniated lumbar disc segments for the 237 herniated lumbar disc cases according to disc severity.

affected site followed by L5-S1 (50.6\% and 40.8\%, respectively).

Modified Korean Oswestry low back pain disability scores

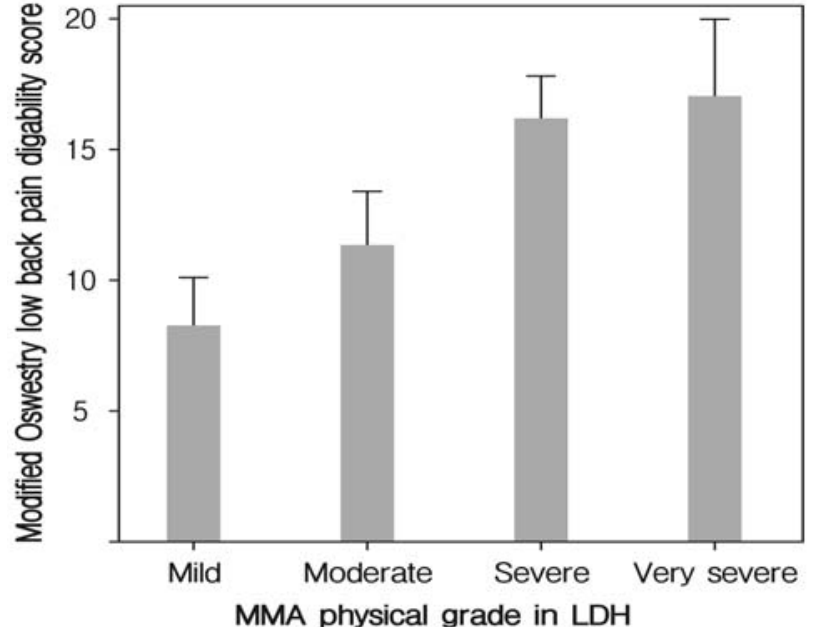

Fig. 5. Relation between modified Korean Oswestry low back pain disability scores and MMA physical grades.

for MMA physical grades are summarized in Fig. 5. Oswestry scores increased with MMA severity, that is, from $8.3 \pm 8.3$ in the mild herniation group, $11.3 \pm 7.9$ in the moderate herniation group, $16.1 \pm 9.7$ in the severe herniation group, to 17.0 \pm 8.1 in the very severe herniation group. Simple linear regression analysis showed that the P-value was $<0.01$.

\section{DISCUSSION}

The first report of a herniated nucleus pulposus in a child was published in 1934, and the first report of surgical treatment in a child (a 12-year-old boy) was issued in $1945^{6,32)}$. Clinical presentations of adolescent $\mathrm{LDH}$ are generally similar of adults ${ }^{25,26}$. However, up to $90 \%$ of adolescent patients have a positive straight-leg raise test ${ }^{7,12)}$, which differentiates adolescent and adult $\mathrm{LDH}$, and is explained by finding that children and adolescents tend to have greater nerve root tension than adults ${ }^{20)}$. Furthermore, this is often accompanied by neurological symptoms, such as, numbness and weakness ${ }^{5,11,24)}$. 
In the past, trauma was considered the main etiological factor of the development of adolescent $\mathrm{LDH}^{2,7,34)}$. However, whereas trauma in adults is mostly often related to lifting or twisting, any severe physical stress on the lumbosacral spine may primarily lead to the onset of symptoms in adolescents. These stresses include a fall, heavy lifting, and extreme flexion-extension, such as, those related to participation in competitive sports. Familial disc disease is considered to be another etiologic factor predisposing adolescent $\mathrm{LDH}^{5,20,28,30)}$, and separation of the posterior ring apophysis of an adjacent vertebral body can sometimes accompany $\mathrm{LDH}^{1,4)}$.

Prevalence studies have reported that $0.5-6.8 \%$ of all patients hospitalized for $\mathrm{LDH}$ are pediatric cases $3,7,8,13,14,16,21,27,31)$. However, the real prevalence of adolescent $\mathrm{LDH}$ is difficult to establish for various reasons, for example, the different age ranges adopted in published series ${ }^{4,13,19,21)}$. A literature review revealed that one previous study addressed the prevalence of Korean adolescent $\mathrm{LDH}^{14)}$. This study was also based on examinations of Korean conscriptees, and found a prevalence of intervertebral disc herniation in adolescent aged at 19 years old and younger of $0.5 \%$ (382 cases among 77,685 examinees), which concurs our result of $0.60 \%$ among 19 -year-old male adolescents. On the other hand, the findings of some reports do not support our findings. An epidemiologic study that followed up 12,058 Finnish babies from birth until 28 years of age, showed that no case of confirmed $\mathrm{LDH}$ until at age of 15 years and a prevalence of only $0.1-0.2 \%$ among 20 years $\mathrm{old}^{33)}$. Furthermore, by 28 years of age, $9.5 \%$ of males and $4.2 \%$ of females were found to have been admitted to hospital with a diagnosis of $\mathrm{LDH}$. These results are quite different to ours, and indicate that a more precise retrospective epidemiologic study is needed.

In the present study, the percentage of disc segments with root compression or significant discogenic spinal stenosis was $29.4 \%$ with an incidence of $0.28 \%$. This percentage is similar to that of reported in another study, in which $\mathrm{LDH}$ with thecal sac compression or significant discogenic spinal stenosis was found to occur in $29 \%$ of disc segments with incidence of $0.28 \%{ }^{15}$. In adult $\mathrm{LDH}$, the prevalence of disc protrusion has been reported to be $16 \%$ and $33 \%{ }^{23,29}$. Regarding herniation severity, serious LDH (thecal sac compression or significant discogenic spinal stenosis) has been reported to be more frequently observed in adolescents than in adults.

In this study, the majority of herniations occurred at low lumbar levels or at the lumbosacral junction $(50.6 \%$ and 40.8 $\%)$, and only a small percentage of herniations were seen at L3/L4 and above. These percentages are similar to those found in previous conscription studies ${ }^{15,18)}$. In adolescent $\mathrm{LDH}$, multiple level involvement suggests that underlying diathesis contributes to development of disc herniation ${ }^{18)}$, and in the pres- ent study, multiple level involvements were observed in 55.7 $\%$ of our 237 subjects with adolescent LDH.

The Oswestry low back pain disability questionnaire was developed for multi-center or national spine surgery surveys. The questionnaire can be easily administered and is capable of detecting functional disability in different spinal disorders ${ }^{17,22)}$. It is divided into ten sections selected from a series of experimental questionnaires designed to assess limitations during various activities, such as, pain intensity, personal care (washing, dressing, etc), lifting, walking, sitting, standing, sleeping, sex life, social life, and travelling'. Each section is scored on a 0-5 scale, where 5 represents greatest disability. In the present study, we used the modified Korean Oswestry low back pain disability questionnaire, but we excluded questions on sex life, because the study subjects were adolescents. Thus, the maximum score of the modified questionnaire as applied was 45 , where scores represent disability.

As shown in Figure 5, modified Korean Oswestry low back pain disability scores increased with herniation severity. According to a previous study ${ }^{9}$, a score of 0-9 represents minimal disability, 10-18 moderate disability, 19-27 severe disability, and 28-36 a crippled status. In the present study, the mild herniation group corresponded to minimal disability, and the moderate, severe, and very severe herniation groups to moderate disability (mean modified Korean Oswestry low back pain disability scores were $8.3 \pm 8.3$ in the mild herniation group, $11.3 \pm 7.9$ in the moderate herniation group, $16.1 \pm 9.7$ in the severe herniation group, and 17.0 \pm 8.1 in the very severe herniation group). Accordingly, Oswestry scores increased with severity, and simple linear regression analysis returned a $p$ value of $<0.05$ for the relation between the two. So, MMA physical grade was found to be an useful measure of disability due to LDH among adolescent males.

\section{CONCLUSION}

In a large cohort of 19-year-old Korean adolescent males in Seoul, Korea, the prevalence of adolescent $\mathrm{LDH}$ was found to be $0.60 \%$ and the prevalence of serious adolescent $\mathrm{LDH}$, which can require management, was found to be relatively high (0.28\%). Multiple levels LDH was slightly more common as $55.7 \%$, and most common affected lesions were not different as the lesions of normal population. MMA physical grade was found to be an accurately measure of disability due to $\mathrm{LDH}$ in adolescent males.

\section{REFERENCES}

1. Banerian KG, Wang AM, Samberg LC, Kerr HH, Wesolowski 
DP: Association of vertebral end plate fracture with pediatric lumbar intervertebral disk herniation: value of CT and MR imaging. Radiology 177:763-765, 1990

2. Bradford DS, Garcia A: Herniation of the lumbar intervertebral disc in children and adolescents. JAMA 210:2045-2051, 1969

3. Borgensen SE, Vang PS: Herniation of the lumbar intervertebral disk in children and adolescents. Acta Orthop Scand 45: 540-549, 1974

4. Callahan DJ, Pack LL, Bream RC, Hensinger RN: Intervertebral disc impingement syndrome in a child: report of a case and suggested pathology. Spine 11:402-404, 1986

5. Clarke NM, Cleak DK: Intervertebral lumbar disc prolapse in children and adolescents. J Pediatr Orthop 3:202-206, 1983

6. DeOrio JK, Bianco AJ: Lumbar disc excision in children and adolescents. J Bone Joint Surg Am 64:991-996, 1982

7. Epstein JA, Epstein NE, Marc J, Rosenthal AD, Lavine LS: Lumbar intervertebral disc herniation in teenage children: recognition and management of associated anomalies. Spine 9: 427432, 1984

8. Epstein JA, Lavine LS: Herniated lumbar intervertebral disc in teenage children. J Neurosurg 2:1070-1075, 1964

9. Fairbank JC, Couper J, Davies JB, O'Brien JP: The Oswestry low back pain disability questionnaire. Physiotherapy 66:271-273, 1980

10. Frymoyer JW, Pope MH, Clements JH, Wilder DG, MacPherson B, Ashikaga T: Risk factors in low-back pain. An epidemiological survey. J Bone Joint Surg Am 65:213-218, 1983

11. Garrido E, Humphreys RP, Hendrick EB, Hoffman HJ: Lumbar disc disease in children. Neurosurgery 2:22-26, 1978

12. Gennuso R, Humphreys RP, Hoffman HJ, Hendrick EB, Drake JM: Lumbar intervertebral disc disease in the pediatric population. Pediatr Neurosurg 18:282-286, 1992

13. Hashimoto K, Fujita K, Kojimoto H, Shimomura Y: Lumbar disc herniation in children. J Pediatr Orthop 10:394-396, 1990

14. Heithoff KB, Gundry CR, Burton CV, Winter RB: Juvenile discogenic disease. Spine 19:335-340, 1994

15. Hong CK, Park CK, Park HC, Yoon SH: Prevalence and clinical characteristics of intervertebral disc herniation in adolescence: a study based on examination for conscription. Korean J Spine 1:83-87, 2004

16. Kurihara A, Kataoka O: Lumbar disc herniation in children and adolescents: a review of 70 operated cases and their minimum 5-year follow-up studies. Spine 5:443-451, 1980

17. Leclaire R, Blier F, Fortin L, Proulx R: A cross-sectional study comparing the Oswestry and Roland-Morris functional disability scales in two populations of patients with low back pain of different levels of severity. Spine 22:68-71, 1997

18. Lee KS, Jeon SS: Analysis of MRI findings of adolescent lumbar disc herniation: comparison with adult lumbar disc hernia- tion findings. J Kor Spine Surg 7:44-52, 2000

19. Luukkonen M, Partanen K, Vapalahti M: Lumbar disc herniations in children: a long-term clinical and magnetic resonance imaging follow-up study. Br J Neurosurg 11:280-285, 1997

20. Matsui H, Kitagawa H, Kawaguchi Y, Tsuji H: Physiological changes of nerve root during posterior lumbar discectomy. Spine 20:654-659, 1995

21. Matsui H, Terahata N, Tsuji H, Hirano N, Naruse Y: Familial predisposition and clustering for juvenile lumbar disc herniation. Spine 17:1323-1328, 1992

22. Niskanen RO: The Oswestry low back pain disability questionnaire. a two-year follow-up of spine surgery patients. Scand J Surg 91:208-211, 2002

23. Ong A, Anderson J, Roche J: A pilot study of the prevalence of lumbar disc degeneration in elite athletes with lower back pain at the Sydney 2000 Olympic Games. Br J Sports Med 37: 263-266, 2003

24. Ozgen S, Konya D, Toktas OZ, Dagcinar A, Ozek MM: Lumbar disc herniation in adolescence. Pediatr Neurosurg 43:7781, 2007

25. Papagelopoulos PJ, Shaughnessy WJ, Ebersold MJ, Bianco AJ Jr, Quast LM: Long-term outcome of lumbar discectomy in children and adolescents sixteen years of age or younger. J Bone Joint Surg Am 80:689-698, 1998

26. Parisini P, Di Silvestre M, Greggi T, Miglietta A, Paderni S: Lumbar disc excision in children and adolescents. Spine 26:19972000, 2001

27. Pietil? TA, Stendel R, Kombos T, Ramsbacher J, Schulte T, Brock M: Lumbar disc herniation in patients up to 25 years of age. Neurol Med Chir (Tokyo) 41:340-344, 2001

28. Postacchini F, Lami R, Pugliese O: Familial predisposition to discogenic low back pain: an epidemiologic and immunogenetic study. Spine 13:1403-1406, 1988

29. Stadnik TW, Lee RR, Coen HL, Neirynck EC, Buisseret TS, Osteaux MJ: Annular tears and disk herniation: prevalence and contrast enhancement on MR images in the absence of low back pain or sciatica. Neuroradiology 206:49-55, 1998

30. Varlotta GP, Brown MD, Kelsey JL, Golden AL: Familial predisposition for the herniation of a lumbar disc in patients who are less than twenty-one years old. J Bone Joint Surg Am 73: 124-128, 1991

31. Wahren H: Herniated nucleus pulposus in a child of twelve years. Acta Orthop Scand 16:40-42, 1945

32. Zamani $\mathrm{MH}$, McEwen GD: Herniation of the lumbar disc in children and adolescents. J Pediatr Orthop 2:528-533, 1982

33. Zitting P, Rantakallio P, Vanharanta H: Cumulative incidence of lumbar disc diseases leading to hospitalization up to the age of 28 years. Spine 23:2337-2343, 1998

34. Zucker L, Amacher AL, Eltomey A: Juvenile lumbar discs. Childs Nerv Syst 3:125-127, 1987 